\begin{tabular}{|c|l|}
\hline Title & Nucleophilic A ddition Reactions of Nitriles to Nitrones under Mild Silylation Conditions \\
\hline Author(s) & Tanino, Keiji; Y oshimura, Fumihiko; A be, Taiki \\
\hline Citation & $\begin{array}{l}\text { Synlett, 25(13), 1863_1868 } \\
\text { https://doi.org/10.1055/s0034_1378274 }\end{array}$ \\
\hline Issue Date & 201408 \\
\hline Doc URL & http://hdl.handle.net/2115/59743 \\
\hline Rights & ○ 2014 Georg Thieme Verlag \\
\hline Type & article (author version) \\
\hline File Information & Synlett_25_1863.pdf \\
\hline
\end{tabular}

Instructions for use 


\title{
Nucleophilic Addition Reactions of Nitriles to Nitrones under Mild Silylation Conditions
}

\author{
Fumihiko Yoshimura, ${ }^{*^{\mathrm{a}}}$ Taiki Abe, ${ }^{\mathrm{b}}$ Keiji Tanino ${ }^{*^{\mathrm{a}}}$ \\ ${ }^{a}$ Department of Chemistry, Faculty of Science, Hokkaido University, Sapporo 060-0810, Japan. \\ ${ }^{\mathrm{b}}$ Graduate School of Chemical Sciences and Engineering, Hokkaido University, Sapporo 060-0810, Japan. \\ Fax: +81-11-706-4920 \\ E-mail: fumi@sci.hokudai.ac.jp (F.Y.); ktanino@sci.hokudai.ac.jp (K.T.) \\ Received: The date will be inserted once the manuscript is accepted.
}

\begin{abstract}
In the presence of triethylsily trifluoromethanesulfonate (TESOTf) and triethylamine $\left(\mathrm{Et}_{3} \mathrm{~N}\right)$, aliphatic nitriles undergo addition reactions with aldonitrones under non-basic mild conditions, providing $O$-triethylsilyl ethers of $\beta-N$-hydroxyamino nitriles with high yields. The reaction appears to proceed via in situ formation of an $N$-silyl ketene imine followed by the Mannich-type reaction.
\end{abstract}

Key words: nucleophilic addition, nitriles, nitrones, amines, hydroxylamine.

The addition reaction of nucleophiles to nitrones is one of the powerful and reliable methods for the synthesis of $\alpha$-branched $N, N$-disubstituted hydroxylamine derivatives. ${ }^{1}$ Among various nucleophiles, organometallic reagents, such as Grignard and organolithium reagents, are frequently used in this type of reactions under basic (anionic) conditions (Scheme 1). ${ }^{1,2}$ Similarly to the Mukaiyama aldol reaction and the Hosomi-Sakurai allylation reactions, silyl enol ethers, silyl ketene acetals, and allylsilanes are also used in this process under acidic conditions (Scheme 1). ${ }^{1,2}$ On the other hand, the addition reactions of nitrones with nitriles are scarcely explored under both basic and acidic conditions. ${ }^{3}$

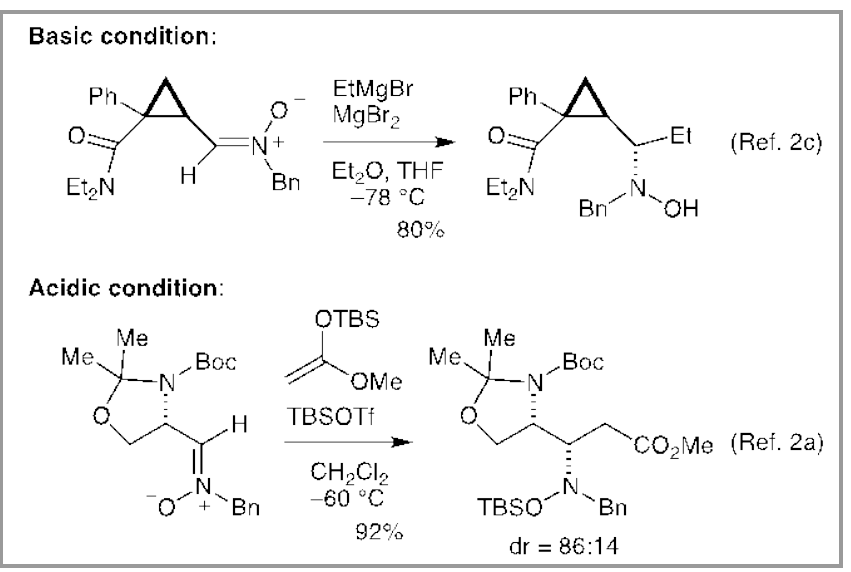

Scheme 1 Typical examples of the nucleophilic addition to nitrones

As a highly competent nitrile anion equivalent, $N$-silyl ketene imines, which are prepared by trapping of the anion with a bulky trialkylsilyl chloride, have been of much interest for the last decade. ${ }^{4}$ While considerable drawbacks remain in their handling and storage due to the high tendency toward hydrolysis, $N$-silyl ketene imines react with a range of carbonyl electrophiles as well as $N$-acylhydrazones and $N$-arylaldimines, ${ }^{5}$ giving rise to the corresponding $\alpha$-substituted nitriles under mild conditions.

In the course of the studies on development of new synthetic reactions using $\alpha$-cyano carbanions, ${ }^{6}$ we recently reported the intramolecular conjugate addition of $\alpha, \beta$-unsaturated lactones having an alkanenitrile side chain promoted by TMSOTf and triethylamine $\left(\mathrm{Et}_{3} \mathrm{~N}\right)$ (Scheme 2, $\left.\quad \mathbf{1} \square 2\right)^{7}{ }^{7}$ The cyclization reaction was supposed to proceed through formation of the $N$-silyl ketene imine intermediate under the influence of TMSOTf and $\mathrm{Et}_{3} \mathrm{~N}$. Indeed, a 85:15 diastereomeric mixture of acyclic nitrile $\mathbf{3}$ was found to undergo isomerization to afford a 60:40 mixture of the diastereomers under a similar conditions. ${ }^{8}$ These results suggested that the combined use of TMSOTf and $\mathrm{Et}_{3} \mathrm{~N}$ shows promise for generating a $N$-silyl ketene imine from the corresponding nitrile without using a strong base such as LDA. ${ }^{9}$

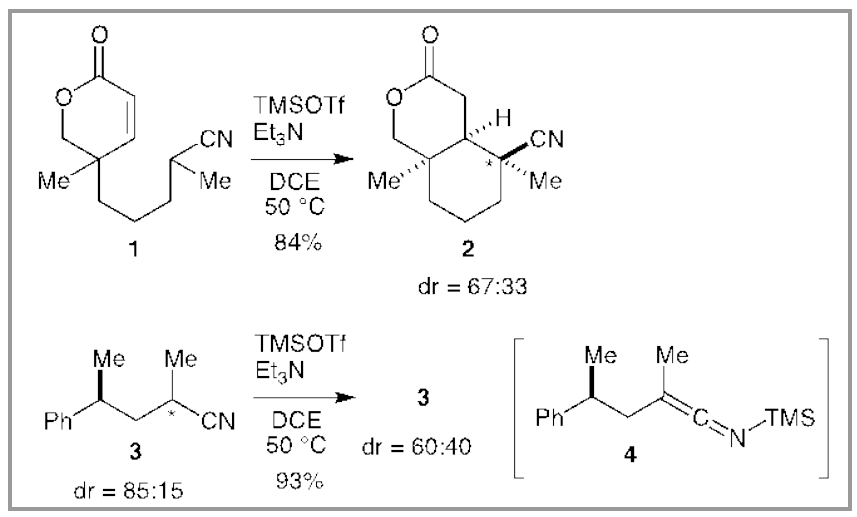

Scheme 2 TMSOTf-Et ${ }_{3} \mathrm{~N}$ promoted intramolecular conjugate addition and its mechanistic investigation

With these findings, we envisaged that the addition reaction between nitrones and nitriles would proceed under mild neutral conditions. Namely, treatment of a mixture of nitrones $\mathbf{5}$ and nitriles $\mathbf{6}$ with trialkylsilyl triflate and $\mathrm{Et}_{3} \mathrm{~N}$ would directly yield $O$-trialkylsilyl $\beta$ hydroxyamino nitrile 7 through the in situ formation of $N$-siloxyiminium ion $\mathbf{8}^{10}$ and $N$-silyl ketene imine $\mathbf{9}$ (Scheme 3). This process would provide a simple and efficient synthetic method for $\beta$-aminonitrile derivatives that are useful synthetic intermediates and important structural motifs in biologically active 
compounds including $\beta$-amino acids and 1,3diamines. $^{11}$

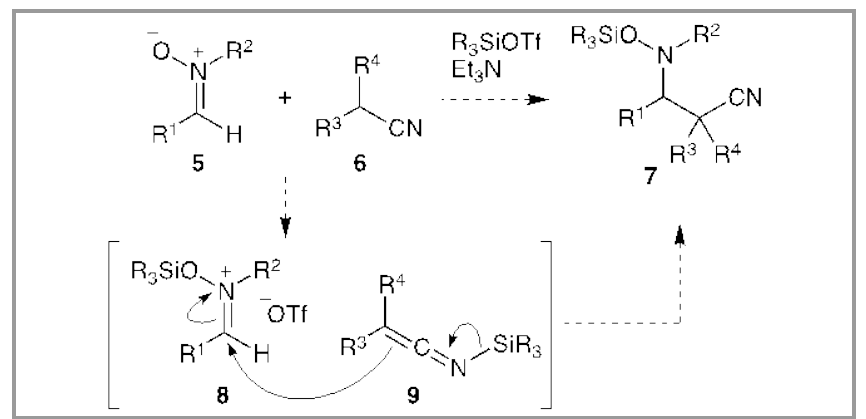

Scheme 3 Proposal for addition reactions of nitriles to nitrones

To ascertain the feasibility of the expected addition reaction, we initially attempted the reaction of $N$ benzylidenemethanamine $N$-oxide (10) with propionitrile (Scheme 4). To our delight, the desired $O$-TMS $\beta$-hydroxyamino nitrile $\mathbf{1 1}$ was obtained in $75 \%$ yield as a 59:41 diastereomeric mixture when nitrone 10 ( 1 equiv) and propionitrile (1 equiv) were treated with TMSOTf ( 2 equiv) and $\mathrm{Et}_{3} \mathrm{~N}$ ( 2 equiv). However, a considerable amount of amide 12, arising from 10 through a rearrangement pathway, ${ }^{12,13}$ was formed in $22 \%$ yield. The reaction of $\mathbf{1 0}$ with 2phenylpropanenitrile (13) gave similar results, and addition product 14a having a quaternary carbon atom was obtained in $75 \%$ yield along with 12 (25\% yield).

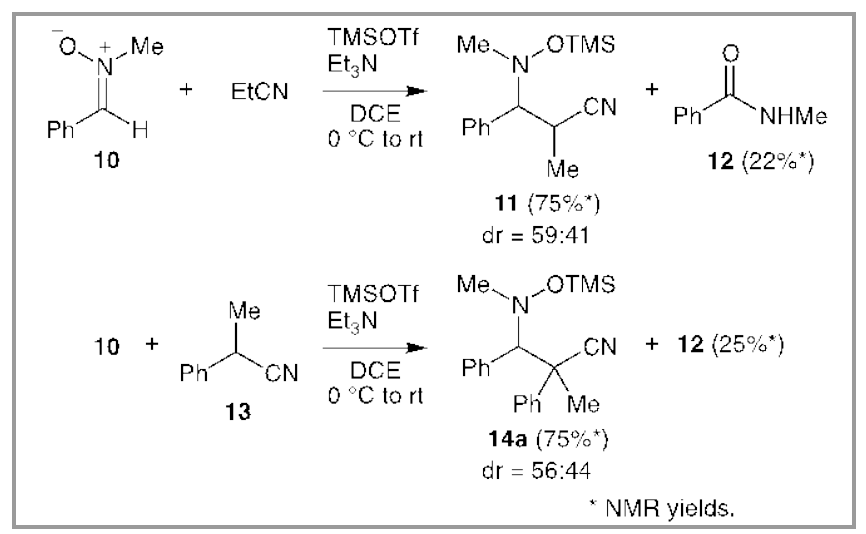

Scheme 4 Preliminary results

With a view to diminishing the competitive rearrangement pathway, the reactions of nitrile $\mathbf{1 3}$ and nitrone $\mathbf{1 0}$ with various silylating agents were explored as shown in Table 1. The use of TMSBr failed to promote the addition reaction, and amide $\mathbf{1 2}$ was obtained as the major product (entry 2). On the other hand, the reaction mediated by $\mathrm{TMSNTf}_{2}{ }^{14}$ afforded $O$-TMS $\beta$-hydroxyamino nitrile 14a in excellent yield (93\% by crude NMR) (entry 3). However, purification of the crude product by silica gel column chromatography suffered from hydrolysis of the silyloxy group, which prompted us to employ more bulky silylating reagents. While the use of tertbutyldimethylsilyl trifluoromethanesulfonate
(TBSOTf) led to poor results (entry 4), triethylsilyl trifluoromethanesulfonate (TESOTf) gave promising results with the stable $O$-TES $\beta$-hydroxyamino nitrile 14c in $80 \%$ yield along with $12 \%$ yield of amide 12 (entry 5). After optimization of the reaction conditions, the best result was obtained at $-30{ }^{\circ} \mathrm{C}$, providing 14c in 94\% yield ( $d r=55: 45$ ) after purification (entry 6).

Note that the reaction with 1.1 equivalents of TESOTf and $\mathrm{Et}_{3} \mathrm{~N}$ at $-30{ }^{\circ} \mathrm{C}$ resulted in the formation of $\mathbf{1 4 c}$ only in $19 \%$ yield along with $49 \%$ of 12 , indicating that the use of two equivalents of both reagents, i.e. stoichiometric amounts, is of critical importance for this reaction. Unfortunately, despite the reaction proceeds with an excellent yield, diastereoselectivity was not induced, likely due to low level of stereodiscrimination in the addition step.

Table 1 Evaluation of silylating agents for the addition reaction of nitrile $\mathbf{1 3}$ to nitrone $\mathbf{1 0}^{\mathrm{a}}$

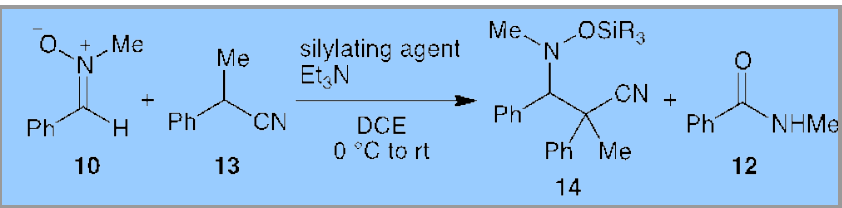

\begin{tabular}{|c|c|c|c|}
\hline \multirow[t]{2}{*}{ Entry } & \multirow[t]{2}{*}{ Silylating agent } & \multicolumn{2}{|c|}{ Yields (\%) $^{\text {b }}$} \\
\hline & & $14(\mathrm{dr})^{\mathrm{C}}$ & 12 \\
\hline 1 & TMSOTf & 14a: $75(56: 44)$ & 25 \\
\hline 2 & $\mathrm{TMSBr}^{\mathrm{d}}$ & 14a: 0 & 75 \\
\hline 3 & TMSNTf $_{2}$ & 14a: 93 (59:41) & 6 \\
\hline 4 & TBSOTf $^{\mathrm{e}}$ & 14b: 57 (51:49) & 42 \\
\hline 5 & TESOTf & 14c: $80(54: 46)$ & 12 \\
\hline 6 & TESOTf $^{\mathrm{f}}$ & 14c: $94^{\mathrm{g}}(55: 45)$ & 0 \\
\hline
\end{tabular}

${ }^{a}$ A mixture of nitrone $10(0.2 \mathrm{mmol})$, nitrile $\mathbf{1 3}(0.2 \mathrm{mmol})$ and $\mathrm{Et}_{3} \mathrm{~N}(0.4 \mathrm{mmol})$ in DCE $(1 \mathrm{~mL})$ was treated with a silylating agent (0.4 mmol) at $0^{\circ} \mathrm{C}$ to rt.

${ }^{\mathrm{b}}$ Yields determined by ${ }^{1} \mathrm{H}$ NMR analysis of the crude product mixture using pyrazine as an internal standard.

${ }^{c}$ Diastereomeric ratios of $\mathbf{1 4}$ are in parenthesis. The relative configuration was not determined.

${ }^{\mathrm{d}}$ Reaction at 0 to $80^{\circ} \mathrm{C}$.

${ }^{\mathrm{e}}$ Reaction at $0{ }^{\circ} \mathrm{C}$.

${ }^{\mathrm{f}}$ Reaction at $-30^{\circ} \mathrm{C}$.

${ }^{\mathrm{g}}$ Isolated yield after silica gel column chromatography on 0.4 mmol scale.

The synthetic advantage of our new method over the conventional method under anionic conditions ${ }^{3}$ was demonstrated in Scheme 5. Thus, the addition reaction of 4-methoxyphenyacetonitrile (15b) to nitrone $\mathbf{1 0}$ under the influence of TESOTf and $\mathrm{Et}_{3} \mathrm{~N}$ gave basesensitive $\beta$-hydroxyamino nitrile $\mathbf{1 6}$ in good yield after removal of the TES group under acidic conditions (85\% yield for 2 steps). In contrast, the $\alpha$ cyano carbanion generated from $\mathbf{1 5 b}$ by LDA underwent the addition reaction with nitrone $\mathbf{1 0}$ to afford 16 only in $48 \%$ yield along with the $\beta$ elimination product $\mathbf{1 7}$ (10\% yield) and recovery of the substrates (10: 21\%; 15b: 35\%). 


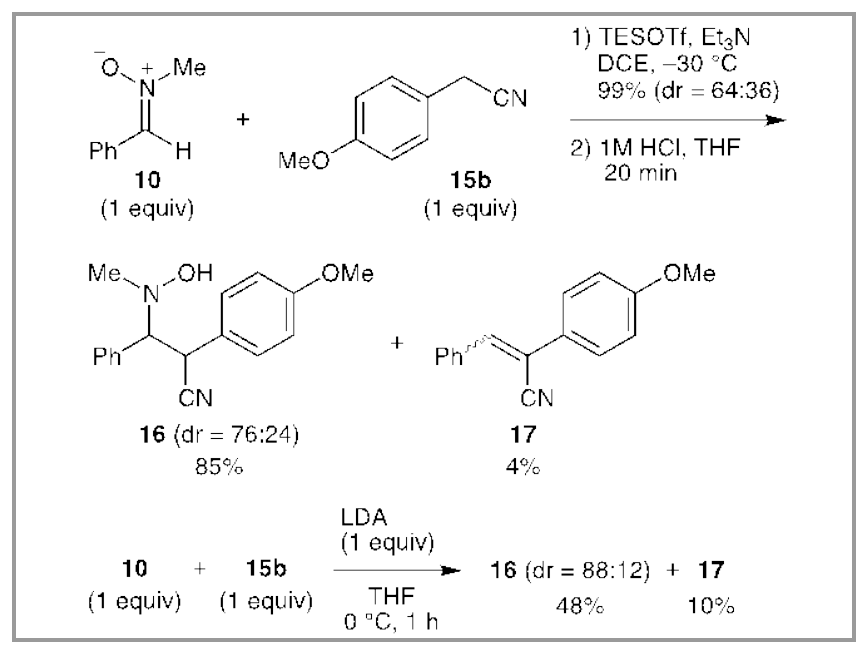

Scheme 5 Comparison with a conventional method

We next applied the optimized reaction conditions using TESOTf to the reactions of nitrone $\mathbf{1 0}$ with a series of nitriles (Table 2). Gratifyingly, simple alkanenitrile 15a, $\alpha$-aryl acetonitriles $15 \mathbf{b}-\mathbf{d}$, and $\alpha$ heteroaryl acetonitriles 15e-g afforded the corresponding $O$-TES $\beta$-hydroxyamino nitriles 18 in good to excellent yields (entries 1-7), although the diastereomeric ratio of $\mathbf{1 8}$ was rather low (74:26 58:42). In the case of the reaction of 2pyridylacetonitrile (15e), TESOTf-Et ${ }_{3} \mathrm{~N}$ reagent triggered the elimination reaction of $O$-TES hydroxylamine from the desired product 18e, giving rise to (Z)-3-phenyl-2-(pyridin-2-yl)acrylonitrile (19) in $38 \%$ yield along with 18e (entry 5). $\alpha, \alpha-$ Disubstituted nitriles including isobutyronitrile (15h) and diphenylacetonitrile (15i) gave addition products having the newly formed quaternary carbon atom in good yields (entries 8 and 9), while two equivalents of nitrile 15h was required in entry 8 because of its low reactivity. Note that the neutral reaction condition using TESOTf-Et ${ }_{3} \mathrm{~N}$ allows the use of nitriles with various functional groups, and chloroacetonitirile (15j) and $N$-(diphenylmethylene)aminoacetonitrile (15k) afforded the desired products in excellent yields, respectively (entries 10 and 11).

Table 2 Reactions of nitrone $\mathbf{1 0}$ with various nitriles $\mathbf{1 5}^{\mathrm{a}}$

Entry<smiles>N#CCc1cccc2ccccc12</smiles>

5<smiles>N#CCc1ccccn1</smiles>

6<smiles>N#CCc1c[nH]c2ccccc12</smiles>

$$
\text { Me }
$$

$$
\left(\mathrm{CH}_{3}\right)_{2} \mathrm{CHCN}(\mathbf{1 5 h})^{\mathrm{e}}
$$

$\mathrm{Ph}_{2} \mathrm{CHCN}(\mathbf{1 5 i})^{\mathrm{g}}$

$\mathrm{ClCH}_{2} \mathrm{CN}(\mathbf{1 5 j})$

11

$$
\text { } \widehat{\mathrm{N}}_{\mathrm{CN15k}}^{\mathrm{Ph}}
$$

18d: $95 \quad 74: 26$

18e: $58^{\mathrm{d}}$

69:31

18f: 95

59:41

18g: $100 \quad 68: 32$

18h: $79^{f}$

18i: $84^{\mathrm{h}}$

18j: 99

18k: 98

$79: 21$

$73: 27$

\footnotetext{
${ }^{a}$ Reaction conditions: nitrone 10 (0.4 mmol), nitrile $15(0.4 \mathrm{mmol})$, TESOTf (0.8 mmol), Et $3 \mathrm{~N}(0.8 \mathrm{mmol}), \mathrm{DCE}(2 \mathrm{~mL}),-30^{\circ} \mathrm{C}$, $0.5 \sim 1.5 \mathrm{~h}$.

${ }^{\mathrm{b}}$ Isolated yield after purification.

${ }^{\mathrm{C}}$ Determined by ${ }^{1} \mathrm{H}$ NMR analysis of the crude product, relative stereochemistry not assigned.

d (Z)-3-Phenyl-2-(pyridin-2-yl)acrylonitrile (19) was obtained in $38 \%$ yield.

${ }^{\mathrm{e}}$ Two equivalents of nitrile were used.

${ }^{\mathrm{f}}$ Yield is based on 10. Amide $\mathbf{1 2}$ was obtained in 13\% yield.

${ }^{\mathrm{g}}-30$ to $0^{\circ} \mathrm{C}, 1.5 \mathrm{~h}$.

${ }^{\mathrm{h}}$ Amide 12 was obtained in $6 \%$ yield.<smiles>N#C/C(=C\c1ccccc1)c1ccccn1</smiles>
}

The scope of nitrones was then examined by using nitrile 15b as a nucleophile (Table 3). Additions of $\mathbf{1 5 b}$ to aromatic nitrones 20a-c proceeded smoothly to furnish the corresponding $O$-TES $\beta$-hydroxyamino nitriles in good to excellent yields (entries 1-3). The chemoselective addition to nitrone moiety was achieved in the reaction of 20c keeping the ester group intact (entry 3). The reaction of endocyclic nitrone 20d provided tetrahydroisoquinoline derivative $21 d$ as a single diastereomer (entry 4). ${ }^{15,16}$ Addition to $\alpha, \beta$ unsaturated nitrone 20e occurred exclusively in a 1,2fasion (entry 5). While the addition reaction was applicable to an $\alpha, \alpha$-disubstituted aliphatic nitrone (entry 6), aliphatic nitrone $\mathbf{2 0 g}$ bearing an acidic $\alpha$ proton failed to react with nitrile $\mathbf{1 5 b}$, resulting in decomposition under the reaction conditions (entry 7). ${ }^{17}$ 

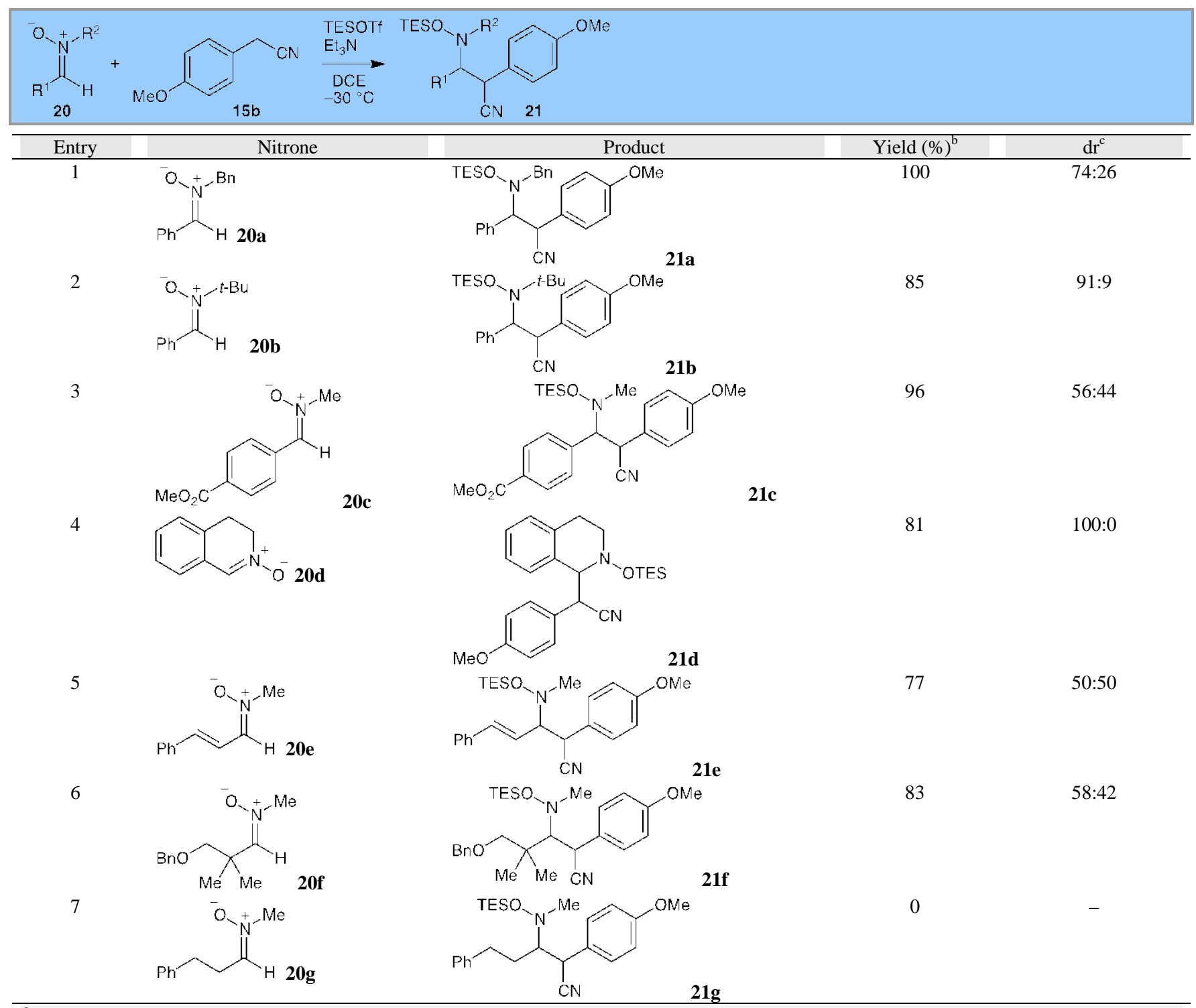

${ }^{\mathrm{a}}$ Reaction conditions: nitrone 20 (1 equiv), nitrile 15b (1 equiv), TESOTf (2 equiv), Et ${ }_{3} \mathrm{~N}$ ( 2 equiv), DCE (0.2 M), -30 to $0{ }^{\circ} \mathrm{C}, 0.5 \sim 3$ h.

${ }^{\mathrm{b}}$ Isolated yield after purification.

${ }^{\mathrm{c}}$ Determined by ${ }^{1} \mathrm{H}$ NMR analysis of the crude product, relative stereochemistry not assigned.

Finally, transformations of the O-TES $\beta$ hydroxyamino nitriles were briefly examined to evaluate the synthetic utility and versatility of the addition products (Scheme 6). Nitrile $\mathbf{1 8 h}$ can be converted to the corresponding amine 22 by treating with $\mathrm{Zn} / \mathrm{H}_{2} \mathrm{SO}_{4}$, whereas treatment of $\mathbf{1 8 h}$ with $\mathrm{Zn} / \mathrm{TFA}$ in $\mathrm{MeOH}$ at $60{ }^{\circ} \mathrm{C}$ afforded amide 23. In addition, nitrile $\mathbf{1 8 h}$ can be converted to $\beta$-amino acid 25 through isoxazolidin-5-one formation followed by $\mathrm{N}-\mathrm{O}$ cleavage under hydrogenation. Furthermore, 1,3diamine derivative $\mathbf{2 6}$ was obtained by reduction of the cyano group using $\mathrm{LiAlH}_{4}$. Conversely, upon treatment with LDA at $0{ }^{\circ} \mathrm{C}$, nitrile 18a underwent 3exo-tet ring closure reaction, ${ }^{18}$ giving rise to $N$ methylaziridine $\mathbf{2 7}$ with high diastereoselectivity.

In conclusion, we developed a novel method for nucleophilic addition reactions of nitriles to nitrones promoted by TESOTf and $\mathrm{Et}_{3} \mathrm{~N}$ under mild conditions. ${ }^{19}$ The reaction appears to proceed via in situ $N$-silyl ketene imine formation followed by the Mannich-type addition reaction. In contrast with the conventional addition reactions using strong bases, the non-basic mild reaction conditions of the present method tolerates various functional groups and usually provides the $\beta$-aminonitrile derivatives in high yields without causing $\beta$-elimination reactions or retro-addition reactions. The new method will offer an efficient route to base-sensitive $\beta$-aminonitrile derivatives, which serve as useful intermediates in the synthesis of biologically important compounds including $\beta$-amino acids and 1,3-diamines. 


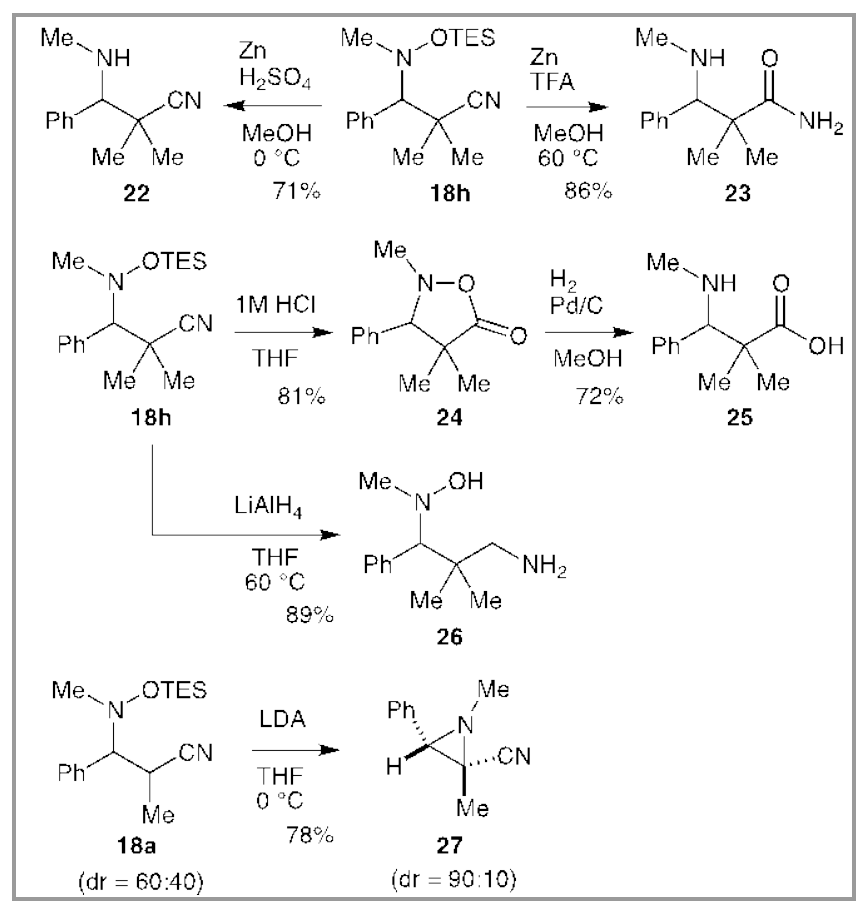

Scheme 6 Transformations of the addition products

Supporting Information for this article is available online at http://www.thiemeconnect.com/ejournals/toc/synlett.

\section{Acknowledgment}

We acknowledge Dr. Eri Fukushi and Mr. Yusuke Takata (GCMS \& NMR Laboratory, Faculty of Agriculture, Hokkaido University) for their mass spectral measurements. This work was supported by JSPS KAKENHI Grant Number 24510290 and the Mitsubishi Tanabe Pharma Award in Synthetic Organic Chemistry, Japan.

\section{References and Notes}

(1) For reviews, see: (a) Bloch, R. Chem. Rev. 1998, 98, 1407; (b) Merino, P.; Franco, S.; Merchan, F. L.; Tejero, T. Synlett 2000, 442; (c) Lombardo, M.; Trombini, C. Synthesis 2000, 759; (d) Merino, P.; Tejero, T. Synlett 2011, 1965.

(2) For typical examples, see: (a) Merino, P.; Franco, S.; Merchan, F. L.; Tejero, T. J. Org. Chem. 2000, 65, 5575; (b) Murahashi, S.; Imada, Y.; Kawakami, T.; Harada, K.; Yonemushi, Y.; Tomita, N. J. Am. Chem. Soc. 2002, 124, 2888; (c) Kazuta, Y.; Abe, H.; Matsuda, A.; Shuto, S. J. Org. Chem. 2004, 69, 9143; (d) Fu, Y.; Liu, Y.; Chen, Y.; Hügel, H. M.; Wang, M.; Huang, D.; Hu, Y. Org. Biomol. Chem. 2012, 10, 7669.

(3) (a) Aurich, H. G.; Schmidt, M.; Schwerzel, T. Chem. Ber. 1985, 118, 1086; (b) Babu, Y. S.; Chand, P.; Ghosh, A. K.; Kotian, P. L.; Kumar, S. Y. PCT Int. Appl. WO 2006002231, 2006; (c) Behr, J.; Chavaria, D.; PlantierRoyon, R. J. Org. Chem. 2013, 78, 11477.

(4) For an excellent review of $N$-silyl ketene imines, see: Denmark, S. E.; Wilson, T. W. Angew. Chem. Int. Ed. 2012, 51, 9980.

(5) (a) Notte, G. T.; Baxter Vu, J. M.; Leighton, J. L. Org. Lett. 2011, 13, 816; (b) Zhao, J.; Liu, X.; Luo, W.; Xie, M.; Lin, L.; Feng, X. Angew. Chem. Int. Ed. 2013, 52, 3473.
(6) (a) Tanino, K.; Tomata, Y.; Shiina, Y.; Miyashita, M. Eur. J. Org. Chem. 2006, 328; (b) Yamada, T.; Yoshimura, F.; Tanino, K. Tetrahedron Lett. 2013, 54, 522.

(7) Yoshimura, F.; Torizuka, M.; Mori, G.; Tanino, K. Synlett 2012, 23, 251.

(8) We could not detect $N$-silyl ketene imine $\mathbf{4}$ when monitoring the reaction by ${ }^{1} \mathrm{H}$ and ${ }^{13} \mathrm{C}$ NMR. The isomerization of $\mathbf{3}$ did not proceed in the absence of either TMSOTf or $\mathrm{Et}_{3} \mathrm{~N}$. Accordingly, very reactive intermediate $\mathbf{4}$ was immediately protonated by triethylamine salt of triflic acid generated in situ as a proton source, providing the isomerized product 3 .

(9) In this connection, Emde and Simchen reported that silylation of acetonitrile with excess TMSOTf and $\mathrm{Et}_{3} \mathrm{~N}$ in ether gave a mixture of $\left(\mathrm{Me}_{3} \mathrm{Si}\right)_{2} \mathrm{C}=\mathrm{C}=\mathrm{N}\left(\mathrm{SiMe}_{3}\right)$ (44\%) and $\left(\mathrm{Me}_{3} \mathrm{Si}\right)_{3} \mathrm{CCN}(56 \%)$, see: Emde, $\mathrm{H}$.; Simchen, G. Synthesis 1977, 6363.

(10) It is reported that the reactions of aldnitrones with TMSOTf afford the corresponding $N$ -

trimethylsiloxyiminium ions which can be identified by NMR spectroscopy, see: Camiletti, C.; Dhavale, D. D.; Gentilucci, L.; Trombini, C. J. Chem. Soc., Perkin Trans. 1 1993, 3157.

(11) (a) Muller, G. W.; Shire, M. G.; Wong, L. M.; Corral, L. G.; Patterson, R. T.; Chen, Y.; Stirling, D. I. Bioorg. Med. Chem. Lett. 1998, 8, 2669; (b) Liu, M.; Sibi, M. P. Tetrahedron 2002, 58, 7991; (c) Fleming, F. F.; Yao, L.; Ravikumar, P. C.; Funk, L.; Shook, B. C. J. Med. Chem. 2010, 53, 7902.

(12) Interestingly, the combination of TMSOTf and $\mathrm{Et}_{3} \mathrm{~N}$ smoothly promoted rearrangement of an aromatic aldonitrone to the isomeric amide (Scheme 7).

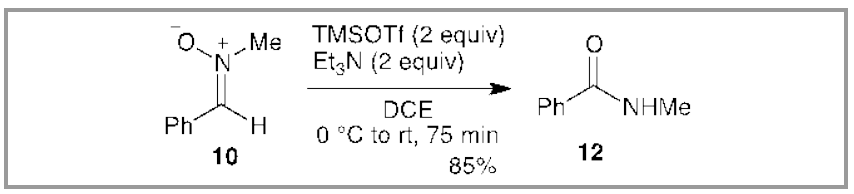

Scheme 7

(13) Hamer, J.; Macaluso, A. Chem. Rev. 1964, 64, 473.

(14) (a) Mathieu, B.; Ghosez, L. Tetrahedron Lett. 1997, 38, 5497; (b) Ishii, A.; Kotera, O.; Saeki, T.; Mikami, K. Synlett 1997, 1145.

(15) All attempts at determination of the relative stereochemistry of nitrile 21d were unsuccessful.

(16) The high stereoselectivity in the formation of nitrile 21d is not well understood.

(17) It is assumed that aliphatic nitrone $\mathbf{2 0} \mathbf{g}$ was decomposed through the formation of the corresponding $N$ triethylsiloxyenamine derivative and subsequent selfcondensation or polymerization.

(18) For related aziridinations, see: (a) Tsuge, O.; Sone, K.; Urano, S.; Matsuda, K. J. Org. Chem. 1982, 47, 5171; (b) Bew, S. P.; Hughes, D. L.; Savic, V.; Soapi, K. M.; Wilson, M. A. Chem. Commun. 2006, 3513.

(19) General procedure (Table 1, entry 6): To a mixture of nitrone 10 (0.4 mmol), nitrile $13(0.4 \mathrm{mmol})$, and $\mathrm{Et}_{3} \mathrm{~N}$ $(0.8 \mathrm{mmol})$ in DCE $(2 \mathrm{~mL})$ was added TESOTf $(0.8$ mmol) at $-30{ }^{\circ} \mathrm{C}$, and the reaction mixture was stirred at this temperature for $30 \mathrm{~min}$. Saturated aqueous sodium bicarbonate $(1 \mathrm{~mL})$ was added to the mixture, and the product was extracted with EtOAc. The combined organic layers were dried over $\mathrm{MgSO}_{4}$ and concentrated under reduced pressure. Purification by flash column chromatography $\left(\mathrm{SiO}_{2}\right.$, hexane- $\left.\mathrm{Et}_{2} \mathrm{O}=15: 1\right)$ afforded $O$-TES $\beta$-hydroxyamino nitrile $14 \mathrm{c}(0.377 \mathrm{mmol}, 94 \%)$. 
Short title for running header

Nucleophilic Addition Reactions of Nitriles to Nitrones

\section{Graphical abstract}

Nucleophilic Addition Reactions of Nitriles to Nitrones under Mild Silylation Conditions

Fumihiko Yoshimura,* Taiki Abe, Keiji Tanino*

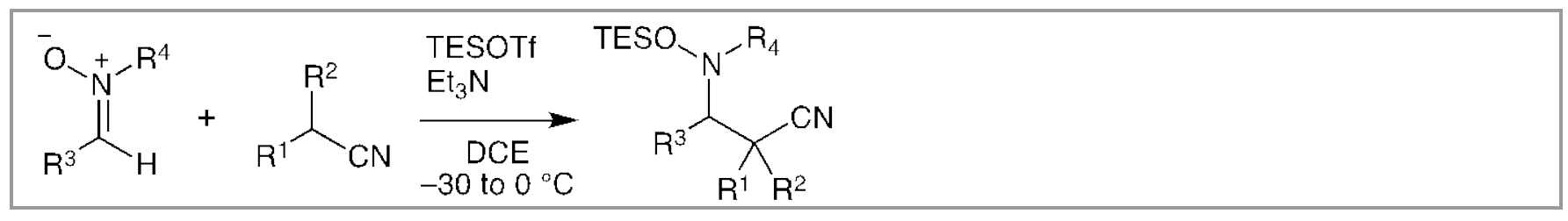

\section{Manuscript submission checklist}

- Statement of significance of work.

- Full mailing address, telephone, and fax numbers and e-mail address of the corresponding author.

- Graphical abstract.

- 5 key words.

- Original Word file.

- Original graphics files.

Proceed to submit your article via our online submission system at http://mc.manuscriptcentral.com/synlett. 